\title{
Glucose-6-phosphate Dehydrogenase Deficiency in Portugal: Biochemical and Mutational Profiles, Heterogeneity, and Haplotype Association
}

Submitted 01/19/02; revised 02/22/02

(Communicated by E. Beutler, M.D., 02/26/02)

\author{
Maria-Odete Rodrigues, ${ }^{1}$ Ana Ponces Freire, ${ }^{2}$ Gisela Martins, ${ }^{1}$ Júlia Pereira, ${ }^{1}$ \\ Maria-do-Carmo Martins, ${ }^{1}$ and Carolino Monteiro ${ }^{3}$
}

\begin{abstract}
Glucose-6-phosphate dehydrogenase (G6PD) deficiency is the most common human enzymopathy. This deficiency in erythrocytes has a prevalence of $0.51 \pm 0.109$ in the Caucasoid male population of Portugal. The frequency for deficiency-conferring genes is $0.39 \%$ in the Portuguese population. In the herein study populations males from areas of Portugal presenting with the highest prevalence of G6PD deficiency (Castelo Branco, Setúbal, Faro, and Lisbon) as well as similar subjects located in the border Center/North area of the country (Viseu) have been analyzed for biochemical parameters and screened for mutations and haplotypeassociated mutations commensurate with G6PD deficiency. Six intragenic restriction fragment length polymorphisms (RFLPs) were studied: exon 5, nt $376 \mathrm{~A} \rightarrow \mathrm{G}$, FokI; intron 5, nt $611 \mathrm{C} \rightarrow \mathrm{G}, P v u \mathrm{II}$; intron 8, nt $163 \mathrm{C} \rightarrow$ T, BspHI; exon 10, nt $116 \mathrm{G} \rightarrow$ A, PstI; exon 11, nt $1311 \mathrm{C} \rightarrow$ T, BclI; and intron 11, nt $93 \mathrm{~T} \rightarrow \mathrm{C}$, NlaIII. New haplotypes were constructed with the inclusion of intron 11, nt $93 \mathrm{~T} \rightarrow \mathrm{C}$, NlaIII, and only 5 of 64 possible haplotypes were found to show a marked linkage disequilibrium for several RFLPs and also for mutations and specific haplotypes. The control population $(n=168$ males) presented the G6PD B variant and corresponded to haplotypes I $(--++--)$, Ia $(--++-+)$, and VIIa $(--++++)$, in $91.8,2.3$, and $5.9 \%$, respectively. The PCR and sequencing analysis of extracted DNAs from the deficient G6PD group showed 48.6\% (16/33) of individuals with the G6PD A- mutation, corresponding to haplotype VIa $(++-+-+)$; $9 \%(3 / 33)$ with the Betica mutation and 18\% (6/33) with the Santa Maria mutation, both of them associated with haplotype IVa (+ $--+-+) ; 6.1 \%(2 / 33)$ with the Mediterranean mutation associated with haplotype VIIa; $12.3 \%$ (4/33) with the Seattle mutation, 3.0\% (1/33) with Gaohe mutation; and a new mutation, 3.0\% (1/33), which we designated by G6PD Flores, all of them associated with haplotype I. $\odot 2002$ Elsevier Science (USA)
\end{abstract}

Key Words: glucose-6-phosphate dehydrogenase (G6PD) deficiency; Portuguese population; G6PD haplotypes; linkage disequilibrium; G6PD epidemiology.

\section{INTRODUCTION}

Glucose-6-phosphate dehydrogenase (G6PD) is a housekeeping enzyme present in all human cells where it plays a key role in the metabolism of glucose and maintenance of glutathione levels that act as sulfhydryl buffers required in turn for the maintenance of cysteine residues of hemoglobin and other distinct proteins of the red cell required for structural integrity of the red cell plasma membrane. Although G6PD provides other functions, it is a critical enzyme of the human red cell since this cell has no mitochondria and thus the only source of reduced NADP is from the activity of G6PD.

G6PD deficiency is the most common enzyme deficiency in the human and it is estimated that this condition affects more than 100 million people throughout tropical and subtropical regions of the world (1). G6PD deficiency has been shown to

\footnotetext{
Correspondence and reprint requests to: Maria-Odete Rodrigues. Fax: 35121752 6400. E-mail: odete.rodrigues@insa.min-saude.pt.

${ }^{1}$ Instituto Nacional de Saúde Doutor Ricardo Jorge, Av Padre Cruz, P-1649-016 Lisbon, Portugal.

${ }^{2}$ Faculdade de Ciências UL, Departamento de Química e Bioquímica, Campo Grande, Edifício C8, 1749-016 Lisbon, Portugal.

${ }^{3}$ Instituto de Higiene e Medicina Tropical and CMDT, Rua Junqueira 96, P-1349-008 Lisbon, Portugal.
} 
be due to enzyme variants that exhibit less than optimum enzyme activity. As many as 400 such variants have been identified, some of which differ remarkably in their electrophoretic and enzymatic properties (2). These variants reflect allelic genes located in the long arm of the $\mathrm{X}$ chromosome (Xq28) and, as shown by molecular epidemiological studies, do not have their origins in early human migrations.

It has been commonly accepted that because Plasmodium falciparum requires products from the pentose phosphate pathway and sources of reduced glutathione for optimum viability, conditions that reduce the levels of these products will render that red cell a poor environment for the parasite, and hence more resistant to infection. Consequently, humans that are heterozygous for G6PD, and therefore have variants of this enzyme that yield less than optimum activity, would be resistant to infection by $P$. falciparum. Furthermore, it is known that the parasitized G6PDdeficient cell is rapidly removed from the circulation, so that the parasite is not afforded the possibility to undergo division (3).

Variants of G6PD have been identified by biochemical analysis and only a small proportion of this heterogeneity has been confirmed at the DNA level by identification of mutations in the G6PD coding sequence and comparison of the gene encoding variant enzymes with the sequence of the normal G6PD gene (4). Because $0.5 \%$ of the Caucasoid male population of Portugal presents with G6PD deficiency (5) we have extended the study of G6PD and its varying status of deficiency to a larger area of Portugal and characterized the variants identified at the level of the gene. The data obtained in part from the use of restriction fragment length polymorphism analysis (RFLP) are of utmost importance for the understanding of genetic association and gene flow in the world.

\section{MATERIALS AND METHODS}

\section{Population}

Blood samples were collected randomly from 13,785 Portuguese Caucasoid males (18-21 years old) living in Portugal devoid of symptoms and clinical data compatible with G6PD deficiency. A second group of blood samples were collected from 33 G6PD-deficient individuals living in Castelo Branco, Setúbal, Lisbon, Faro, and Viseu districts.

Blood samples were also collected from a Caucasoid male population of same age range and from the same districts. This group would serve as an additional control specific for the areas under study.

\section{Laboratory}

Biochemical characterization. All blood samples collected in tubes containing EDTA as anticoagulant were screened using the NADP reduction fluorescent method thereby affording the identification of the G6PD-deficient males $(5,6)$.

A semipurified G6PD extract was prepared from blood samples of each of the three above groups according to standard methods recommended by the World Health Organization scientific group (1) and analyzed for G6PD activity, electrophoretic mobility, $K_{\mathrm{m}} \mathrm{G} 6 \mathrm{P}, K_{\mathrm{m}} \mathrm{NADP}$, and ability to use substrate analogs (2-deoxyglucose 6-phosphate and galactose 6-phosphate). Suitable and appropriate controls were run in parallel for each of the analyses performed.

During the evaluation of G6PD activity, the laboratory participated in the UK National External Quality Assessment Scheme for Haematology surveys for red cell enzymes (G6PD). During the work the results were corrected with deviation index close to zero for the three groups of specimen analyzed in each assay.

\section{Amplification of Genomic DNA}

Genomic DNA was extracted from peripheral blood leukocytes by the procedure described by Miller et al. (7).

The entire coding region of G6PD gene was amplified by the polymerase chain reaction (PCR) using $100 \mathrm{ng}$ of genomic DNA, 25 pmol of each oligonucleotide (described in Table 1 and Table 2), $0.2 \mathrm{mM}$ of each dNTP (Pharmacia), $0.2 \mathrm{U}$ DNA polymerase (AmpliTaq, Perkin-Elmer), $1 \times$ 
TABLE 1

Primers for PCR Amplification Reactions

\begin{tabular}{|c|c|c|}
\hline Exon/intron & Primers $\left(5^{\prime} \rightarrow 3^{\prime}\right)$ & Amplified product $(\mathrm{bp})$ \\
\hline E-2 & CTCTAgAAAggggCTAACTTCTCAAggAATTCCTggCTTTTAAgATTggg & 242 \\
\hline E-3 & gTgTCCCCAgCCACTTCTAAACAgCTgTAACCAgTgCgg & 166 \\
\hline E-4 & ACTggTTACAgCTgTgCCCTTggTAgAgAgggCAgAACCA & 185 \\
\hline $\mathrm{E}-3+4^{a}$ & CAgCCACTTCTAACCACAACCAggCTgggggAg & 315 \\
\hline E-5 & AgACCCTCCACTCCCCTggCAAgCCTTACATCTggCTC & 319 \\
\hline E-5.1 & AgAACACACACggACTCAAAgAgTAggAggCTgCATCATCgTACT & 154 \\
\hline E-5.2 & gCTggCCAgTACgATgATgAACggCAAgCCTTACATCTg & 176 \\
\hline I-5 & gAACAgggAggAgATgTggTTgAggAggTTCTggCCTCTACTC & 199 \\
\hline E-6 & AgCAgAggCTggAACCggCACCTCAgCACCATgAggT & 167 \\
\hline E-7 & AgTTCCTCCACCTTgCCCTgAACTgCAgggTgAggAg & 264 \\
\hline $\mathrm{E}-6+7^{a}$ & ACTCCCCgAAgAggggTCCAgCCTCCCAggAgAgA & 545 \\
\hline $\mathrm{I}-7^{b}$ & TggACCCCTACACAgCCAAgTACggCATgCTCCTgggACTgCT & 342 \\
\hline E-8 & ggAgCTAAggCgAgCTCCATgCTCTTggggACTg & 162 \\
\hline $\mathrm{I}-8$ & CATCTgTgACgAggCACTgAgCTggTCACATAgTgACTgTCAgg & 167 \\
\hline E-9 & CAAggAgCCCATTCTCTTgCCTTgCTgggCCTCg & 253 \\
\hline E-10.1 & CTggTCCACACCCTgAgAgAgCTTgCACTgCTggTggAAgAT & 160 \\
\hline E-10.2 & AgTTCCATgATgTggCCgACTgCTCCTTCTCTgTAgggC & 196 \\
\hline E-11 & ggAgCAgTgTggAgggTgATAgCCCACAggTATgCAgg & 206 \\
\hline E-12 & CTgCATACCTgTgggCTATggAggCATgAggTAgCTCCAC & 252 \\
\hline E-13.1 & AgCTACCTCATgCCTCTCCTCTgCAgCTgAggTCAATggTC & 226 \\
\hline E-13.2 & CCgAgTCgggAggACTCgggACAgACgAATgggC & 241 \\
\hline E-13.3 & CTgTCCCAgAgCTTATTggCTTCTTATAgCAgAGAggCTgCC & 253 \\
\hline E-13.4 & gTCACCAgCAACATCTCgAAgCAAATgACAAggggACAg & 192 \\
\hline $\mathrm{I}-7$ & TggACCCCTACACAgCCAAgTACggCATgCTCCTgggACTgCT & 342 \\
\hline
\end{tabular}

${ }^{a}$ From Poggi et al. (33).

${ }^{b}$ From Vulliamy et al. (12). The remaining primers were designed by us.

reaction buffer $(10 \times$ PCR Buffer, Perkin-Elmer) in a final volume of $50 \mu \mathrm{l}$, in a Perkin-Elmer Thermocycler 9600 .

\section{Restriction Fragment Length Polymorphism (RFLP) Analysis}

A strategy based upon sequential steps was performed. The relevant segments of DNA were amplified using PCR and tested for the presence of the $376 \mathrm{~A} \rightarrow \mathrm{G}$ mutation leading to the G6PD A variation, using the restriction endonuclease FokI. The digested samples (+) were analyzed for the $202 \mathrm{G} \rightarrow$ A mutation characteristic of G6PD $\mathrm{A}-$ by digestion with NlaIII restriction endonuclease. The G6PD Betica mutation, $968 \mathrm{~T} \rightarrow \mathrm{C}$ was screened using $M s p$ I restriction endonuclease.

Samples which were not G6PD A, FokI (-), were then screened for the $563 \mathrm{C} \rightarrow \mathrm{T}$ mutation, G6PD Mediterranean, using MboII restriction endonuclease. When this mutation was absent the
$844 \mathrm{G} \rightarrow \mathrm{C}$ a mutation was detected in exon 8 , G6PD Seattle, using DdeI restriction endonuclease (Table 3).

All restriction digestions were performed according to the manufacturer's instructions (New England Biolabs).

\section{Single-Strand Conformation Polymorphism (SSCP) Analysis}

Samples not presenting known mutations were screened by SSCP analysis $(8,9)$ by using 2 $\mu \mathrm{l}$ of PCR amplified DNA and $2 \mu \mathrm{l}$ of a solution containing 95\% formamide (Kodak), $50 \mathrm{mM}$ EDTA- $\mathrm{Na}_{2}$ (BDH Chemicals), 0.3\% bromophenol blue (Difco) and 0.3\% xylenocyanol (Merck) and heating to $95^{\circ} \mathrm{C}$ for $3 \mathrm{~min}$ followed by rapid cooling to $4^{\circ} \mathrm{C}$. Electrophoresis was performed in a nondenaturing $0.5 \times \mathrm{MDE}$ gel (FMC) at $40 \mathrm{~W}$ at room temperature in $0.6 \times \mathrm{TBE}$ buffer. The gel was stained by the $\mathrm{AgNO}_{3}$ method for the visualization of the bands. Any mobility shift of sin- 
TABLE 2

PCR Conditions

\begin{tabular}{lcccc}
\hline & \multicolumn{2}{c}{ Annealing } & & \\
\cline { 2 - 3 } $\begin{array}{l}\text { Exon (E)/ } \\
\text { intron (I) }\end{array}$ & $\begin{array}{c}\text { Temp } \\
\left({ }^{\circ} \mathrm{C}\right)\end{array}$ & $\begin{array}{c}\text { Time } \\
(\mathrm{s})\end{array}$ & $\begin{array}{c}\text { Extension } \\
\text { time }(\mathrm{s})\end{array}$ & $\begin{array}{c}\text { Number of } \\
\text { cycles }\end{array}$ \\
\hline E-2 & 53 & 60 & 90 & 35 \\
E-3 & 60 & 45 & 60 & 30 \\
E-4 & 60 & 60 & 90 & 30 \\
E-3 + 4 & 59 & 20 & 30 & 30 \\
E-5 & 58 & 45 & 60 & 30 \\
E-5.1 & 60 & 30 & 45 & 30 \\
E-5.2 & 60 & 30 & 45 & 30 \\
I-5 & 64 & 20 & 30 & 30 \\
E-6 & 62 & 30 & 45 & 30 \\
E-7 & 65 & 45 & 80 & 35 \\
E-6 + 7 & 60 & 30 & 45 & 30 \\
I-7 & 59 & 60 & 90 & 30 \\
E-8 & 58 & 45 & 60 & 38 \\
I-8 & 59 & 60 & 60 & 30 \\
E-9 & 59 & 20 & 30 & 35 \\
E-10.1 & 64 & 20 & 30 & 30 \\
E-10.2 & 64 & 20 & 30 & 30 \\
E-11 & 62 & 30 & 60 & 30 \\
E-12 & 59 & 30 & 45 & 35 \\
E-13.1 & 64 & 30 & 45 & 35 \\
E-13.2 & 59 & 30 & 60 & 30 \\
E-13.3 & 60 & 30 & 45 & 35 \\
E-13.4 & 60 & 30 & 45 & 35 \\
\hline & & & &
\end{tabular}

gle-stranded DNA fragment compared with the normal control was indicative of an alteration.

Sequence Analysis

Fragments showing a mobility shift by SSCP analysis were sequenced using a direct PCR sequencing procedure by the dideoxy chain-termination method (10).

Amplified DNA was purified by the QIA quick-spin PCR purification kit (Qiagen) and the sequencing reactions were performed using the Amplicycle sequencing kit (Perkin-Elmer) incorporating $\left[{ }^{35} \mathrm{~S}\right] \mathrm{dCTP}$ (Amersham). The detected mutations were confirmed by sequencing the opposite strand.

\section{Haplotype Analysis}

Six intragenic polymorphic sites were analyzed: exon 5, nt 376 A $\rightarrow$ G, FokI, intron 5, nt $611 \mathrm{C} \rightarrow \mathrm{G}, P v u \mathrm{II}$, intron 8 , nt $163 \mathrm{C} \rightarrow \mathrm{T}, B s p H \mathrm{I}$, exon 10 , nt $116 \mathrm{G} \rightarrow \mathrm{A}$, Pst I exon 11, nt 1311 $\mathrm{C} \rightarrow \mathrm{T}$, BclI and intron 11, nt $93 \mathrm{~T} \rightarrow \mathrm{C}$, NlaIII. Polymorphisms were recorded as $(+)$ if the restriction site was present and as (-) if it was absent (Table 4).

\section{RESULTS}

Following a study of prevalence of G6PD deficiency in the universal male conscription for military service in Portugal $(n=13785)$, Martins et al. found a prevalence of $0.51 \pm 0.109$ (5). The frequency of G6PD deficiency-conferring genes in the male population of Portugal determined by our study is 0.39 (Table 5).

Within this population the highest values of prevalence were found for individuals from the districts of Castelo Branco, Setúbal, Faro, and Lisbon and from the area of the border Center/ North of the country, Viseu (Fig. 1).

The enzymatic activity of G6PD, the kinetic properties of G6P and NADP, the ability of the enzyme to use the substrate analogs 2-deoxy-G6P and galacto-6-phosphate, and the electrophoretic mobility of the enzyme were assayed for erythrocytes obtained from individuals from the control

TABLE 3

Restriction Enzyme Digestion of PCR Products for Mutation Screening

\begin{tabular}{lllll}
\hline & & & \multicolumn{2}{c}{ Fragment size (bp) } \\
\cline { 4 - 5 } \multicolumn{1}{c}{ Mutation } & Exon & Restriction enzyme & \multicolumn{1}{c}{ Normal } & \multicolumn{1}{c}{ Mutated } \\
\hline A & 5 & FokI & 319 & 211,108 \\
A- & $3+4$ & NlaIII & 315 & 219,96 \\
Mediterranean & $6+7$ & MboII & $374,120,20,31$ & $274,100,120,25,20,31$ \\
Seattle & 8 & Del $\mathrm{I}$ & 157,5 & $101,56,5$ \\
Betica & 9 & MspI & 253 & 138,115 \\
\hline
\end{tabular}


TABLE 4

Intragenic G6PD Polymorphisms Detected by PCR-RFLP

\begin{tabular}{lccc}
\hline & & \multicolumn{2}{c}{ Fragment size (bp) } \\
\cline { 3 - 4 } $\begin{array}{c}\text { Restriction } \\
\text { enzyme }\end{array}$ & Exon/intron & $\begin{array}{c}\text { Not digested } \\
(-)\end{array}$ & $\begin{array}{c}\text { Digested } \\
(+)\end{array}$ \\
\hline FokI & E.5 & 319 & 211,108 \\
$P v u I \mathrm{II}$ & I.5 & 199 & 150,49 \\
BspHI & I.8 & 168 & 116,52 \\
PstI & E.10.1 & 160 & 117,43 \\
BclI & E.11 & 207 & 184,23 \\
NlaIII & I.11 & 252 & 177,75 \\
\hline
\end{tabular}

and G6PD-deficient populations, both of which are from the above districts. In addition, mutation screening and construction of haplotypes were performed.

\section{Mutation Analysis}

Due to the geographical location of Portugal and the ensuing contributions made by non-European populations, two main mutations were expected: African G6PD A - and G6PD Mediterra- nean. Thus, all samples were analyzed for G6PD $\mathrm{B}$ and G6PD A by digesting with FokI (exon 5, nt $376 \mathrm{~A} \rightarrow \mathrm{G}$ ), yielding a prevalence for each mutation of $8 / 33$ and $25 / 33$, respectively, and thus in turn providing the grouping of samples into two groups that could now be further screened for G6PD A and African A- mutation by digesting with NlaIII (exon 4, nt $202 \mathrm{G} \rightarrow$ A) and for the Mediterranean mutation by digesting with $\mathrm{MboII}$ (exon 6 , nt $563 \mathrm{C} \rightarrow \mathrm{T}$ ) $(2 / 8)$. The remaining nine mutations out of twenty five G6PD A were screened for the Betica mutation by digesting with MspI (exon 9, nt $968 \mathrm{~T} \rightarrow \mathrm{C}$ ) yielding three positive for the Betica mutation. Six G6PD Bdeficient samples negative for the Mediterranean mutation were digested with $D d e \mathrm{I}$ to check for the Seattle mutation (exon 8, nt $844 \mathrm{G} \rightarrow \mathrm{C}$ ) yielding four that were positive for this mutation.

The remaining two G6PD B and the six G6PD A were then screened by SSCP analysis thus affording a detection of any shift in band due to a variance of sequence. This procedure allowed detection of one G6PD Gaohe (exon 2, nt $95 \mathrm{~A} \rightarrow$

TABLE 5

Frequency of the G6PD Gene Deficiency in Portugal

\begin{tabular}{|c|c|c|c|c|c|c|}
\hline \multirow[b]{2}{*}{ District } & \multicolumn{3}{|c|}{ Population $\left(10^{3}\right)$ in 1988} & \multirow{2}{*}{$\begin{array}{c}\text { Number of } \\
\text { screened } \\
\text { male }\end{array}$} & \multirow{2}{*}{$\begin{array}{c}\% \\
\text { deficiency }\end{array}$} & \multirow{2}{*}{$\begin{array}{c}\% \text { in } \\
\text { population }\end{array}$} \\
\hline & Total & Male & Female & & & \\
\hline Aveiro (C) & 667.9 & 324.7 & 343.2 & 724 & 0.41 & 0.29 \\
\hline Beja $(S)$ & 176.6 & 88.4 & 88.2 & 634 & 0.31 & 0.20 \\
\hline Braga $(\mathrm{N})$ & 774.9 & 378.2 & 396.7 & 398 & 0 & 0 \\
\hline Bragança $(\mathrm{N})$ & 184.3 & 93.5 & 90.8 & 282 & 0 & 0 \\
\hline Castelo Branco (C) & 222.5 & 108.3 & 114.2 & 432 & 1.85 & 2.66 \\
\hline Coimbra (C) & 446.5 & 212.3 & 234.2 & 1,205 & 0.17 & 0.10 \\
\hline Évora (S) & 173.6 & 184.8 & 88.8 & 623 & 0.16 & 0.09 \\
\hline Faro $(\mathrm{S})$ & 342.1 & 168.4 & 173.7 & 767 & 1.04 & 1.06 \\
\hline Guarda (N) & 195.1 & 95.1 & 100.0 & 301 & 0.00 & 0.00 \\
\hline Leiria (C) & 436.0 & 213.7 & 222.3 & 428 & 0.93 & 0.90 \\
\hline Lisboa (C) & 2127.6 & 1003.0 & 1124.6 & 2,536 & 0.83 & 0.76 \\
\hline Portalegre (S) & 136.8 & 67.2 & 69.6 & 523 & 0.38 & 0.26 \\
\hline Porto $(\mathrm{N})$ & 1676.9 & 810.3 & 866.6 & 2,024 & 0.05 & 0.03 \\
\hline Santarém (C) & 460.2 & 222.9 & 237.3 & 419 & 0.72 & 0.62 \\
\hline Setúbal (C) & 789.2 & 385.0 & 404.2 & 874 & 1.37 & 1.63 \\
\hline Viana do Castelo & 266.5 & 123.7 & 142.8 & 376 & 0 & 0 \\
\hline Vila Real (S) & 262.5 & 130.3 & 131.9 & 428 & 0 & 0 \\
\hline Viseu $(\mathrm{C})$ & 422.3 & 206.7 & 215.6 & 811 & 0.12 & 0.07 \\
\hline Total & 9761.2 & 4716.5 & 5044.7 & 13,785 & $0.51^{a}$ & 0.39 \\
\hline
\end{tabular}

Note. N, North; C, Center; S, South.

${ }^{a}$ Poisson distribution. Confidence limit 95\%; G6PD deficiency prevalence $=0.51 \pm 0.109$. 

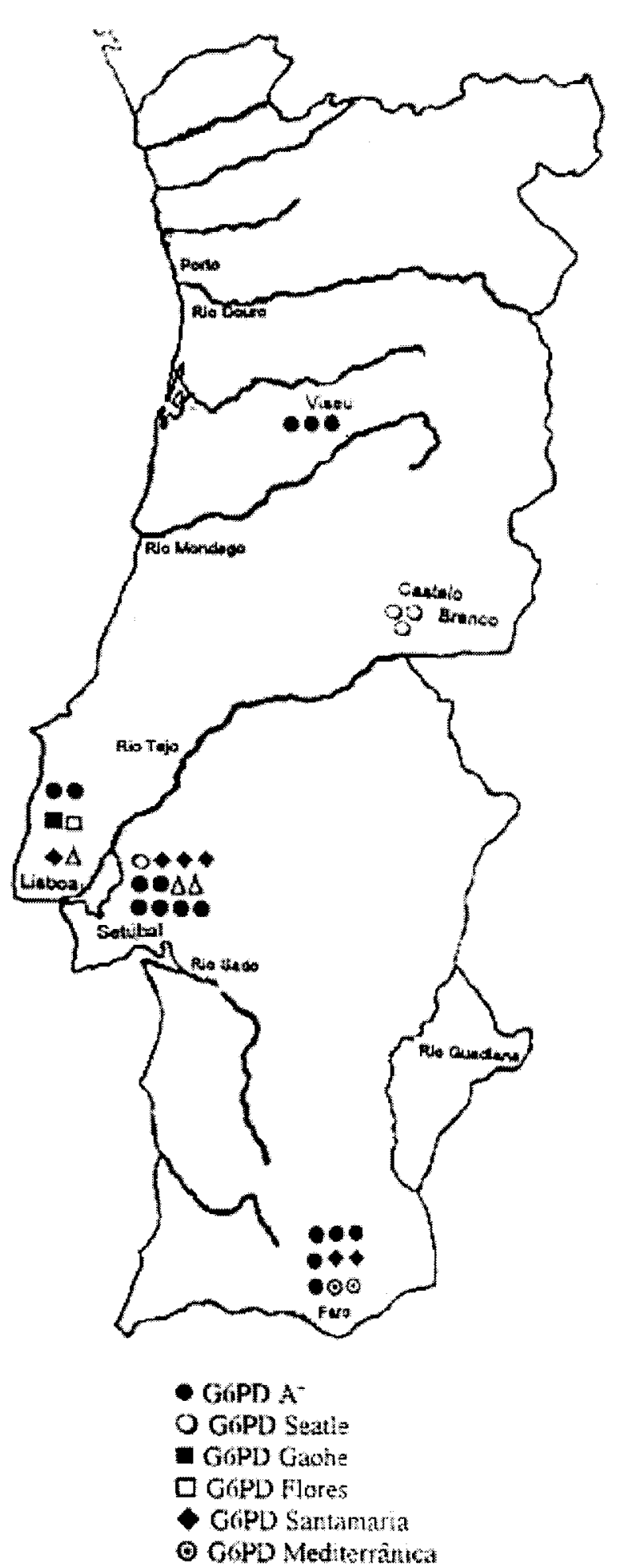

$\triangle$ Gopo Betcis

FIG. 1. Map of Portugal with the geographic distribution of the detected mutations.

G) and one new mutation G6PD Flores (exon 12, nt $1387 \mathrm{C} \rightarrow \mathrm{A}$ ) (11). Employing AccI digestion, six G6PD Santa Maria mutations (exon 6, nt 542 $\mathrm{A} \rightarrow \mathrm{T}$ ) were also identified (Table 6).

\section{Haplotype Analysis}

Six intragenic restriction fragment length polymorphisms (RFLPs) were studied: exon 5 , nt $376 \mathrm{~A} \rightarrow \mathrm{G}$, FokI; intron 5, nt $611 \mathrm{C} \rightarrow \mathrm{G}, P v u \mathrm{II}$; intron 8, nt $163 \mathrm{C} \rightarrow \mathrm{T}$, BspHI; exon 10, nt 116 $\mathrm{G} \rightarrow \mathrm{A}$, PstI; exon 11, nt $1311 \mathrm{C} \rightarrow \mathrm{T}$, BclI; and intron 11, nt $93 \mathrm{~T} \rightarrow \mathrm{C}$, NlaIII. Linkage disequilibrium for several RFLPs and also for mutations and specific haplotypes were studied. Results are described in Tables 4, 8, and 9-12.

\section{Biochemical Phenotypes}

Biochemical characterization was carried out on 19 of the G6PD-deficient males by determining the enzymatic activity in red blood cells The electrophoretic mobility; $K_{\mathrm{m}}$ G6P and $K_{\mathrm{m}}$ NADP and the ability to use substrate analogues were determined for a semipurified enzyme extract. Three G6PD-deficient individuals were characterized only for enzyme activity and electrophoretic mobility.

The obtained results are shown in Table 7 per mutation group. The control population $(n=50)$ was similarly studied and thus provided reference values for the Portuguese population.

\section{DISCUSSION}

In Portugal the prevalence of G6PD deficiency in Caucasoid males is $0.51 \pm 0.109$ (5) but this distribution is not homogeneous throughout the country (Table 5). In this study we describe biochemical characteristics of enzymes associated with G6PD deficiency, the mutations and their frequencies associated with this condition and the haplotypes of 33 G6PD-deficiency individuals from the four areas of Portugal presenting with the highest prevalence of this deficiency as well as from the region in the Center/North border of the country (Viseu) which had escaped previous study.

We observed only two mutations with enzymatic activity $<2 \%$ (Santa Maria and Mediterranean). The study of three G6PD-deficient individuals was limited to the determination of enzymatic activity and the electrophoretic mobility. 
TABLE 6

G6PD-Detected Mutations

\begin{tabular}{|c|c|c|c|c|}
\hline G6PD mutation & Number of cases & Exon & $\begin{array}{c}\text { Genomic nucleotide } \\
\text { substitution }\end{array}$ & $\begin{array}{l}\text { Amino acid } \\
\text { substitution }\end{array}$ \\
\hline $\mathrm{A}-$ & 16 & $202 \stackrel{5}{G} \rightarrow A$ & $\begin{array}{l}376 \mathrm{~A} \rightarrow \mathrm{G} \\
68 \mathrm{Val} \rightarrow \mathrm{Met}\end{array}$ & 126 Asn $\rightarrow$ Asp \\
\hline Santa Maria & 6 & $\begin{array}{l}5 \\
6\end{array}$ & $\begin{array}{l}376 \mathrm{~A} \rightarrow \mathrm{G} \\
542 \mathrm{~A} \rightarrow \mathrm{T}\end{array}$ & $\begin{array}{l}126 \text { Asn } \rightarrow \text { Asp } \\
181 \text { Asp } \rightarrow \text { Val }\end{array}$ \\
\hline Betica & 3 & $\begin{array}{c}5 \\
968 \mathrm{~T} \rightarrow \mathrm{C}\end{array}$ & $\begin{array}{l}376 \text { A } \rightarrow \text { G } \\
323 \text { Leu } \rightarrow \text { Pro }\end{array}$ & 126 Asn $\rightarrow$ Asp \\
\hline Seattle & 4 & 8 & $844 \mathrm{G} \rightarrow \mathrm{C}$ & $282 \mathrm{Asp} \rightarrow \mathrm{His}$ \\
\hline Mediterranean & 2 & 6 & $563 \mathrm{C} \rightarrow \mathrm{T}$ & $188 \mathrm{Ser} \rightarrow \mathrm{Fel}$ \\
\hline Flores & 1 & 12 & $1387 \mathrm{C} \rightarrow \mathrm{A}$ & $463 \mathrm{Arg} \rightarrow$ Ser \\
\hline Gaohe & 1 & 2 & $95 \mathrm{~A} \rightarrow \mathrm{G}$ & $32 \mathrm{His} \rightarrow \mathrm{Arg}$ \\
\hline
\end{tabular}

Enzymatic activity (percentage of normal) of G6PD among these three individuals is variable and ranges from 1.6 (class 2, WHO) to 19.8 (class 3 , WHO).

The ability to distinguish the mutations of G6PD is not possible from the evaluation of biochemical parameters alone; only a genetic profile of each G6PD-deficient individual allowed such identification. The genetic profile also afforded the basis for understanding the effects of these mutations on the biochemical parameters selected for study.

Six intragenic restriction fragment length polymorphisms (RFLPs) were studied and new haplotypes were constructed. Only 5 of 64 possi- ble haplotypes were found showing a marked linkage disequilibrium for several RFLPs and also for mutations and specific haplotypes.

In a control population ( $n=168$ males $)$ we established haplotype-associated genes including the intron 11 NlaIII site. All presented the G6PD $\mathrm{B}$ variant and were associated with haplotypes I $(--++--)$, Ia $(--++-+)$, and VIIa $(--++++)$, in $91.8,2.3$, and $5.9 \%$, respectively.

The molecular characterization of the G6PDdeficient males from families consist of parents and grandparents that have resided in the same area of residence, $48.6 \%(16 / 33)$ show the mutation G6PD A-, African type, haplotype VIa; $18 \%$

TABLE 7

Biochemical Phenotypes of All G6PD Mutations Detected

\begin{tabular}{|c|c|c|c|c|c|c|c|}
\hline \multirow[b]{2}{*}{ G6PD mutation } & \multirow[b]{2}{*}{$\begin{array}{l}\text { Activity } \\
\text { (Ul/g Hb) }\end{array}$} & \multirow[b]{2}{*}{$\%$ normal } & \multirow[b]{2}{*}{$\begin{array}{c}K_{\mathrm{m}} \mathrm{G} 6 \mathrm{P} \\
(\mu \mathrm{mol})\end{array}$} & \multirow[b]{2}{*}{$\begin{array}{c}K_{\mathrm{m}} \text { NADP } \\
(\mu \mathrm{mol})\end{array}$} & \multicolumn{2}{|c|}{ Utilization } & \multirow[b]{2}{*}{$\begin{array}{c}\text { Mobility } \\
\text { TBE }\end{array}$} \\
\hline & & & & & $\begin{array}{c}\text { 2-Deoxy- } \\
\text { G6P }\end{array}$ & Gal 6P & \\
\hline Normal B & $5.48 \pm 1.64$ & 100.0 & $56.83 \pm 8.9$ & $3.98 \pm 1.24$ & $3.17 \pm 1.12$ & $2.82 \pm 0.78$ & Normal \\
\hline Mediterranean $^{a}$ & $0.096 \pm 0.01$ & 1.8 & $15.2 \pm 1.8$ & $1.3 \pm 0.14$ & $35.0 \pm 3.0$ & $41.00 \pm 1.2$ & Normal \\
\hline Seattle $\mathrm{e}^{b}$ & $1.09 \pm 0.14$ & 19.8 & $20.1 \pm 3.6$ & $2.8 \pm 0.31$ & $9.30 \pm 1.1$ & $6.40 \pm 0.5$ & Normal \\
\hline Santa Maria ${ }^{c}$ & $0.09 \pm 0.02$ & 1.6 & $21.2 \pm 5.1$ & $1.5 \pm 0.12$ & $26.0 \pm 3.4$ & ND & Normal \\
\hline $\mathrm{A}-^{d}$ & $0.74 \pm 0.13$ & 13.5 & $31.9 \pm 4.3$ & $2.6 \pm 0.56$ & $5.2 \pm 2.8$ & $3.90 \pm 1.8$ & $>$ Normal \\
\hline Betica $^{e}$ & $0.29 \pm 0.07$ & 5.2 & ND & ND & ND & ND & $>$ Normal \\
\hline Gaohe $f$ & $0.65 \pm 0.14$ & 11.0 & ND & ND & ND & ND & $<$ Normal \\
\hline Flores $^{g}$ & $0.69 \pm 0.14$ & 16.4 & ND & ND & ND & ND & Normal \\
\hline
\end{tabular}

Note. ND, not determined.

${ }^{a}$ Mean $X \pm 1 \mathrm{~s}, n=2$ (duplicate).

${ }^{b}$ Mean $X \pm 1 \mathrm{~s}, n=4$ (duplicate).

${ }^{c}$ Mean $X \pm 1 \mathrm{~s}, n=6$ (duplicate).

${ }^{d}$ Mean $X \pm 1 \mathrm{~s}, n=10$ (duplicate).

${ }^{e-g}$ Mean $X \pm 1 \mathrm{~s}, n=1$ (triplicate). 
TABLE 8

G6PD Intragenic Polymorphism Frequencies in the Control and in the G6PD-Deficiency Populations

\begin{tabular}{|c|c|c|c|c|c|c|c|c|c|c|}
\hline \multirow{3}{*}{$\begin{array}{l}\text { Nucleotide } \\
\text { substitution }\end{array}$} & \multirow[b]{3}{*}{ Exon/intron } & \multirow{3}{*}{$\begin{array}{l}\text { Restriction } \\
\text { enzyme }\end{array}$} & \multicolumn{4}{|c|}{$\begin{array}{l}\text { Allele frequency, control population } \\
\qquad(n=168)\end{array}$} & \multicolumn{4}{|c|}{$\begin{array}{c}\text { Allele frequency, G6PD- } \\
\text { deficiency population }(n=33)\end{array}$} \\
\hline & & & \multicolumn{2}{|c|}{+} & \multicolumn{2}{|c|}{-} & \multicolumn{2}{|c|}{+} & \multicolumn{2}{|c|}{-} \\
\hline & & & $n$ & $\%$ & $n$ & $\%$ & $n$ & $\%$ & $n$ & $\%$ \\
\hline $376 \mathrm{~A} \rightarrow \mathrm{G}$ & Exon 5 & FokI & 0 & 0 & 168 & 100 & 25 & 75.7 & & 24.3 \\
\hline $611 \mathrm{C} \rightarrow \mathrm{G}$ & Intron 5 & $P v u \mathrm{II}$ & 0 & 0 & 168 & 100 & 16 & 48.6 & 1 & 51.4 \\
\hline $163 \mathrm{C} \rightarrow \mathrm{T}$ & Intron 8 & BspHI & 168 & 100 & 0 & 0 & 8 & 24.3 & 2 & 75.7 \\
\hline $1116 \mathrm{G} \rightarrow \mathrm{A}$ & Exon 10 & Pst $\mathrm{I}$ & 168 & 100 & 0 & 0 & 33 & 100 & & 0 \\
\hline $1311 \mathrm{C} \rightarrow \mathrm{T}$ & Exon 11 & $B c l \mathrm{I}$ & 10 & 5.9 & 158 & 94.1 & 2 & 6 & 3 & 94 \\
\hline $93 \mathrm{~T} \rightarrow \mathrm{C}$ & Intron 11 & NlaIII & 14 & 8.3 & 154 & 91.7 & 27 & 81.8 & 6 & 18.2 \\
\hline
\end{tabular}

(6/33) the mutation G6PD Santa Maria; 9\% (3/33) the mutation G6PD Betica, both associated with haplotype IVa; $6.1 \%$ (2/33) the mutation G6PD Mediterranean, haplotype VIIa; $12.3 \%$ (4/33) the mutation G6PD Seattle; 3\% (1/33) the G6PD Gaohe; and a new mutation, G6PD Flores (11) all associated with haplotype I (Table 11).

We were able to expand, with the introduction of the NlaIII allele, the haplotype profile described by Vulliamy et al. (12), and Nafa et al. (13), now designated by haplotype Ia, IVa, VIa and VIIa with the information of the intron 11 NlaIII restriction enzyme site-NlaIII (+) - and the absence of the restriction site, haplotypes I, IV, VI and VII-NlaIII (-).

Table 8 shows that the polymorphisms FokI $(+)$ and $P v u I I(+)$ that are not present in the control population are present in the affected population with frequencies of 75.7 and $48.6 \%$, respectively. NlaIII $(+)$ polymorphism in the control population $(8.3 \%)$ is far lower than

\section{TABLE 9}

G6PD B-Associated Haplotypes-G6PD FokI (-)

G6PD gene polymorphisms

G6PD FokI PvuII BspHI PstI BclI NlaIII Haplotype

\begin{tabular}{llllllll}
\hline B & - & - & + & + & - & - & I \\
B & - & - & + & + & - & + & Ia \\
B & - & - & + & + & + & + & VIIa \\
Gaohe & - & - & + & + & - & - & I \\
Mediterranean & - & - & + & + & + & + & VIIa \\
Seattle & - & - & + & + & - & - & I \\
Flores & - & - & + & + & - & - & I \\
\hline
\end{tabular}

that present in the G6PD-deficient population (81.8\%). Both BspHI (+) and PstI (+) alleles show a frequency of $100 \%$ in the control population. The latter also shows a $100 \%$ frequency in the affected population whereas the former polymorphism shows a frequency of $24.3 \%$ in this population. The polymorphism BclI (+) shows similar frequencies in both groups, $5.9 \%$ and $6 \%$, respectively. We may conclude that the G6PD mutation-associated RFLPs in the Portuguese Caucasoid population are NlaIII (+) in intron 11, FokI (+) in exon 5 and $P v u I I(+)$ in intron 5.

In Table 12 we observe that haplotype I (- $++--)$ is predominant in the Caucasoid control population $(91.8 \%)$, and haplotypes VIa $(++-+-+)$ and IVa $(+--+-+)$ in the affected population, 48.5 and $27.3 \%$, respectively.

In the G6PD-deficient population and in the control one (Tables 9, 10, and 12) the analysis of the six polymorphisms showed only 5 of the 64 possible haplotypes revealing a strong linkage disequilibrium between the RFLPs and also between the G6PD mutated genes and specific haplotypes.

\section{TABLE 10}

G6PD A-Associated Haplotypes-G6PD FokI (+)

\begin{tabular}{lcccccccc}
\hline & \multicolumn{8}{c}{ G6PD gene polymorphisms } \\
\cline { 2 - 8 } Mutation & FokI & PvuII & BspHI & PstI & BclI & NlaIII & Haplotype \\
\hline Betica & + & - & - & + & - & + & IVa \\
Santa Maria & + & - & - & + & - & + & IVa \\
A- & + & + & - & + & - & + & VIa \\
\hline
\end{tabular}




\section{TABLE 11}

Frequency of G6PD-Deficiency Mutation-Associated Haplotypes

\begin{tabular}{lccc}
\hline \multicolumn{1}{c}{ Mutation } & $n$ & $\%$ & Haplotype \\
\hline $\mathrm{A}-$ & 16 & 46.8 & VIa \\
$376 \mathrm{~A} \rightarrow \mathrm{G}$ & & & \\
$202 \mathrm{G} \rightarrow \mathrm{A}$ & 3 & 9.0 & IVa \\
Betica & & & \\
$376 \mathrm{~A} \rightarrow \mathrm{G}$ & & 18.0 & IVa \\
$968 \mathrm{~T} \rightarrow \mathrm{C}$ & & & \\
Santa Maria & 6 & 6.1 & VIIa \\
$376 \mathrm{~A} \rightarrow \mathrm{G}$ & & 3.0 & I \\
$542 \mathrm{~A} \rightarrow \mathrm{G}$ & 2 & 12.3 & I \\
$\begin{array}{l}\text { Mediterranean } \\
563 \mathrm{C} \rightarrow \mathrm{T}\end{array}$ & & & I \\
Gaohe & 1 & 3.0 & \\
$95 \mathrm{~A} \rightarrow \mathrm{G}$ & 4 & & \\
Seattle & & & \\
$844 \mathrm{G} \rightarrow \mathrm{C}$ & 1 & 100 & \\
Flores & & & \\
$1387 \mathrm{C} \rightarrow \mathrm{A}$ & 33 & &
\end{tabular}

None of the G6PD B-deficient individuals, FokI (-) presented the restriction site for $P v u I I$ and $64 \%(16 / 25)$ of the affected FokI $(+)$ (Table 10). This restriction site is common to all G6PD $\mathrm{A}-$. The Pst $\mathrm{I}(+)$ allele is present in both groups of individuals both Fok $(-)$ and $(+)$ (Tables 9 and 10).

Epidemiological studies described by Kay et al. (14), led to the hypothesis that PstI polymorphism arose before the African G6PD A- mutation and that the polymorphisms PstI and $B c l$ I are in linkage disequilibrium. Our study cannot test this hypothesis since the PstI site is not polymorphic. Chromosomes without the PstI restriction site may not have entered the population under study, and if they did in the past may not have been retained due to selection pressures.

The polymorphism $1311 \mathrm{BclI}(+)$ is present in $25 \%$ (2/8) G6PD B-, FokI (-) and absent in all FokI (+) individuals. Such polymorphism is restricted to the Mediterranean mutation thus being in linkage disequilibrium with this mutation.

The G6PD A variant shows the restriction site for FokI (+), making it possible to distinguish it from the G6PD B, FokI (-).

According to Kay et al. (14), the G6PD A is more recent. The G6PD A - $202 \mathrm{~A} \rightarrow \mathrm{G}$, NlaIII $(+)$, is in linkage disequilibrium with the restric- tion site PvuII (+). Therefore, our data support Kay et al.. hypothesis (14), in which the PvuII polymorphism occurred before the NlaIII one because the $P v u I I(+)$ allele is restricted to this group of individuals.

The haplotype-associated G6PD A 376 A $\rightarrow$ $\mathrm{G}$ origin mutations IV and VI, here designated as IVa and VIa with the gain of the Intron 11 NlaIII site, were described by Vulliamy et al. (12). Among these, the Betica mutation was described in Spain $(15,16)$ and the Santa Maria mutation in Costa Rica $(17,18)$ and in Algeria (13). In Portugal the Betica mutation was found in Setúbal and Lisbon and Santa Maria mutation in Lisbon, Setúbal and Faro, and absent in the northern part of the country. The G6PD A - mutation is present in the north, center and south. The predominance of mutations in genes G6PD A $376 \mathrm{~A} \rightarrow \mathrm{G}$ FokI $(+)$ in Portugal, $75.7 \%$ (25/33), is most likely the consequence of the past miscegenation between the Negroid and Caucasoid groups as previously described for sickle cell anemia $(5,19,20)$.

The G6PD Mediterranean mutation detected in individuals from the area of Faro is associated with the same haplotype described in Europe and Middle-East (21-23), which reflects the geographic location of Portugal.

The G6PD Seattle found in the areas of Castelo Branco and Setúbal was previously detected in Scotland (24) in Israel (25), in Greece (26) and in Germany (27). Recently, by the use of molecular analysis, the G6PD Seattle mutation was found in Spain (28), in the Canary Islands $(29,30)$ and in the north African Berber (30). Nafa et al. (13) found the Seattle mutation associated with haplotype $(--++--)$ in Algeria and, and Medina et al. found in England an association to

\section{TABLE 12}

RFLP-Based Haplotypes in the G6PD Control Population

\begin{tabular}{lcrr}
\hline & & \multicolumn{2}{c}{ Control population } \\
\cline { 3 - 4 } & Haplotype & $n$ & $\%$ \\
\hline I & --++-- & 154 & 91.8 \\
Ia & --++-+ & 4 & 2.3 \\
IVa & +--+-+ & - & - \\
VIa & ++-+-+ & - & - \\
VIIa & --++++ & 10 & 5.9 \\
\hline
\end{tabular}


the same haplotype although restricted to four RFLPs (PvuII, PstI, BclI, and NlaIII) (31). Our study in the Portuguese population shows that the haplotype associated G6PD Seattle mutation is the same as that described by Nafa et al. (13) and by Medina et al. (31).

In 1496 adult Jews were expelled from Portugal. Jewish children, however, were retained. Jews could stay with their children if they converted to Christianity (32). Jews that remained were primarily concentrated in the district area of Castelo Branco. The Seattle mutation identified in the people of Palestine, the area from which Portuguese Jews originated during the Diaspora period, and the identification of this mutation almost exclusively within the Castelo Branco area, support the contention that those individuals presenting with this mutation are the progeny of those Jews who remained in that region after 1496.

The haplotype I-associated G6PD Gaohe mutation was found in the area of Setúbal. This mutation had its origins in China (1). We have also identified in Lisbon the new mutation, G6PD Flores, associated with haplotype I (11).

G6PD-deficient populations of African origin-FokI (+) 28/28 chromosomes-studied by Vulliamy et al. (12) showed the intron 11 NlaIII (+) polymorphism, haplotype VIa, and the NlaIII (-) allele in Europeans (42/45 chromosomes), haplotype IV. Nafa et al. (13), did not find in the population from Algeria the NlaIII $(+)$ allele polymorphism associated with the African G6PD A - mutation, haplotypes IV and VI. Xu et al. in the population of the Canary Island (29) and Medina et al. in Mexico (31), detected the NlaIII (+) associated with the FokI $(+)$, haplotype VIa. Our results are in accordance with Vulliamy et al. (12) and $\mathrm{Xu}$ et al. (29) and Medina et al. (31). Accordingly, the NlaIII polymorphism is more recent than the Betica and Santa Maria mutations.

Nafa et al. (13) and Xu et al. (29) detected in G6PD-deficient FokI (-) the G6PD Mediterranean mutation, haplotype VIIa, the G6PD Seattle and G6PD Gaohe mutations, both associated with haplotype I. These studies are in agreement with our results.

The G6PD mutations detected in our study probably express population characteristics result- ing from the incursions and invasions by peoples from as far away as the Far East, the Middle East, and Africa and together support the contention that in Portugal, the origins of G6PD emanate from areas of the World as far away as China, and which during the ensuing centuries, have been incorporated into the Portuguese population in accordance with distinct geographical locations of the country where these people had originally settled.

\section{ACKNOWLEDGMENTS}

We thank Professor Filomena Exposto and Professor Leonard Amaral for helpful comments. Professor Ernest Beutler is acknowledged for critical review of the manuscript.

\section{REFERENCES}

1. Betke, K., Brewer, G. J., Kirkman, H. N., Luzzatto, L., Motulsky, A. G., Ramot, B., and Siniscalco, M. (1967) Standardization of procedures for the study of glucose-6-phosphate dehydrogenase. WHO Tech. Rep. Ser. 366, 30-43.

2. Beutler, E. (1992) Glucose-6-phosphate dehydrogenase deficiency. N. Engl. J. Med. 324, 169-174.

3. Luzzatto, L., Usanga, E. A., and Reddy, S. (1969) Glucose 6-phosphate dehydrogenase deficient red cells: Resistance to infection by malarial parasites. Science 164, 839-842.

4. Beutler, E. (1992) The molecular biology of G6PD variants and other red cell enzyme defects. Ann. Hum. Genet. 43, 47-55.

5. Martins, M. C., Olim, G., Melo, J., Magalhães, H. A., and Rodrigues, M. O. (1993) Hereditary anaemias in Portugal: Epidemiology, public health significance and control. J. Med. Genet. 30, 325-329.

6. Beutler, E. (1983) Glucose-6-phosphate dehydrogenase. In Metabolic Basis of Inherited Diseases (Stanburg, J. B., Wynagaarden, J. B., Brown, M. S., Frederickson, D. S., and Goldstein, J. L., Eds.), 5th ed., pp. 1629-1653. McGraw-Hill, New York, NY.

7. Miller, S. A., Dykes, D. D., and Polesky, H. F. (1988) A simple salting out procedure for extracting DNA from human nucleated cells. Nucleic Acids Res. 16, 1215-1219.

8. Orita, M., Iwahara, H., Kanazawa, H., Hayashi, K., and Sekiya, T. (1989) Detection of polymorphisms of human DNA by gel electrophoresis as single strand conformation polymorphisms. Proc. Natl. Acad. Sci. USA 86, 2766-2770. 
9. Orita, M., Suzuki, Y., Sekiya, T., and Hayashi, K. (1989) Rapid and sensitive detection of point mutations and DNA polymorphisms using the polymerase chain reaction. Genomics 5, 874-879.

10. Sanger, F., Nickeen, S., and Coutson, R. (1977) DNA sequencing with chain termination inhibitions. Proc. Natl. Acad. Sci. USA 74, 5463-5464.

11. Rodrigues, M. O., Pereira, J., Gaspar, G., Martins, M. C., and Monteiro, C. (1997) A novel point mutation in exon 12 on the glucose-6-phosphate dehydrogenase gene: G6PD Flores. Med. Genet. 9, 259.

12. Vulliamy, T. J., Othman, A., Town, M., Natwani, A., Falusi, A. G., Mason, P. J., and Luzzatto, L. (1991) Polymorphic sites in the African population detected by sequence analysis of the glucose-6-phosphate dehydrogenase gene outline the evolution of the variants G6PD A and A-. Proc. Natl. Acad. Sci. USA 88, 8568-8571.

13. Nafa, K., Reghis, A., Osmani, N., Baghli, L., Abbes, H., Benabadji, M., Kaplan, J. C., Vulliamy, T., and Luzzatto, L. (1994) At least five polymorphic mutants account for the prevalence of glucose-6-phosphate dehydrogenase deficiency in Algeria. Hum. Genet. 94, 513-517.

14. Kay, A. C., Kuhl, W., Prchal, J., and Beutler, E. (1992) The origin of glucose-6-phosphate dehydrogenase (G6PD) polymorphisms in African-Americans. Am. J. Hum. Genet. 50, 394-398.

15. Vives-Corrons, J. L., Pujades, A., and Cunia, M. D. (1980) Caracterization molecular de la glucose-6fosfato deshydrogenase (G6PD) en 24 casos de deficit enzimatico y descripcion de una nueva variante (G6PD-Betica). Sangre (Banc) 25, 1049-1053.

16. Beutler, E., Kuhl, W., Vives-Corrons, J. L., and Prchal, J. Y. (1989) Molecular heterogeneity of glucose-6-phosphate dehydrogenase A-. Blood 74, $2550-2555$.

17. Saenz, G. F., Chaves, M., Berrantes, A., Elizondo, J., Monteiro, A. G., and Yoshida, A. (1984) A glucose6-phosphate dehydrogenase variant $\mathrm{Gd}(-)$ Santamaria found in Costa Rica. Acta Haematol. 72, 37-40.

18. Beutler, E. (1991) Glucose-6-phosphate dehydrogenase deficiency. N. Engl. J. Med. 324, 169-174.

19. Monteiro, C., Rueff, J., Falcão, A. B., Portugal, S., Weatherall, D. J., and Kulozik, A. E. (1989) The frequency and origin of the sickle cell mutation in the district of Coruche/Portugal. Hum. Genet. 82, 255258.

20. Lavinha, J., Gonçalves, J., Faustino, P., Romão, L., Osório-Almeida, L., Peres, M. J., Picanço, I., Martins, M. C., Ducrocq, R., Labie, D., and Krishnamoorthy, R. (1992) Importation route of the sickle cell trait into Portugal: Contribution of molecular epidemiology. Hum. Biol. 64, 891-901.

21. Beutler, E., and Kuhl, W. (1990) The nt 1311 poly- morphism of G6PD: G6PD Mediterranean mutation may have originated independently in Europe and Asia. Am. J. Hum. Genet. 47, 1008-1012.

22. Kurdi-Haider, B., Mason, P. J., Berrebi, A., AnkraBadu, G., Al-Ali, A., Oppenheim, A., and Luzzatto, L. (1990) Origin and spread of the glucose-6-phosphatedehydrogenase variant (G6PD Mediterranean) in the Middle East. Am. J. Hum. Genet. 47, 1013-1019.

23. Ruzzo, A., Ninfali, P., and Magnani, M. (1993) Glucose-6-phosphate dehydrogenase nucleotide 1311 polymorphism in central Italy (Marche Region). Enzyme Protein 47, 22-26.

24. Kirkman, H. (1962) Electrophoretic differences of human erythrocyte glucose-6-phosphate dehydrogenase. Am. J. Dis. Child. 104, 566-570.

25. Ramot, B., Bauminger, S., Brock, F., Gafni, D., and Schwartz, J. (1964) Caracterization of glucose-6phosphate dehydrogenase in Jewish mutants. J. Lab. Clin. Med. 64, 895-904.

26. Motulsky, A. G., Stransky, E., and Frasa, G. R. (1964) Glucose-6-fosfato dehydrogenase (G6PD) deficiency, thalassaemia and abnormal haemoglobins in the Philippines. J. Med. Genet. 1, 102-106.

27. Shows, T. B., Tashian, R. E., Brewer, G. J., and Dern, R. J. (1964) Erythrocyte glucose-6-phosphate dehydrogenase in Caucasians: New inherited variant. Science 145, 1056-1064.

28. Rovira, A., Vulliamy, T., Pujedes, M. A., Luzzatto, L., and Vivves-Corrons, J. L. (1995) Molecular genetics of glucose-6-phosphate dehydrogenase (G6PD) deficiency in Spain: Identification of two new point mutations in the G6PD gene. Br. J. Haematol. 91, 66-71.

29. Xu, W., Westwood, B., Bartsocas, C., MalcorraAzpiazu, J. J., Indrák, K., and Beutler, E. (1995) Glucose-6-phosphate dehydrogenase mutations and haplotypes in various ethnic groups. Blood 85, 257263.

30. Cabrera, U. M., Gonzalez, P., and Salo, W. L. (1996) Human enzyme polymorphism in the Canary Islands. VII. G6PD Seattle in Canarians and North African Berbers. Hum. Hered. 46, 197-200.

31. Medina, M. D., Vaca, G., Guido-Lopez, B., Westwood, B., and Beutler, E. (1997) Molecular genetics of glucose-6-phosphate dehydrogenase deficiency in Mexico. Blood Cells Mol. Dis. 23, 88-94, doi: 10.1006/bcmd.1997.0124.

32. Schwarz, S. (1925) Os Cristãos-Novos em Portugal no século XX. Arqueol. História 4, 6-45.

33. Poggi, V., Town, M., Foulkes, N., and Luzzatto, L. (1990) Identification of a single base change in a new human mutant glucose-6-phosphate dehydrogenase gene by polymerase-chain-reaction amplification of the entire coding region from genomic DNA. Biochem. J. 2171, 157-160. 